\title{
Eric Sabourin
}

Doutor em Antropologia, Pesquisador do CIRAD (França). E-mail: eric.sabourin@cirad.fr

\section{Miguel Ângelo Lazzaretti}

Mestre em Sociologia, Professor Assistente da UNIOESTE (Toledo-

PR).E-mail:miglazza@hotmail.com

\section{CONSTRUÇÃO DA AÇÃO COLETIVA NOS SINDICATOS RURAIS BRASILEIROS: ASPECTOS COMPARATIVOS}

\section{RESUMO}

Este artigo estuda a construção coletiva dos temas de ação e de representação no marco da organização dos Sindicatos de Trabalhadores Rurais (STRs). Baseiase no acompanhamento das atividades de STRs em alguns municípios do oeste do Paraná e do Nordeste semi-árido. A questão é discutida na primeira parte referente à região de Toledo, Paraná, e na segunda ao Nordeste semi-árido. O texto é concluído com a análise do perfil e do papel das lideranças sindicais.

Palavras-chaves: organização de produtores, ação coletiva, sindicatos rurais

\section{ABSTRACT}

This article deals with the collective construction of action and representation themes in the organization of Brazilian smallholder's unions (the Sindicatos de Trabalhadores Rurais-STR). It is based on the monitoring of STR's activities in municipalities of the West region of Paraná state and the Semi-Arid Northeast area. The first part analyses the relationship between STR representation and action and the evolution of family agriculture in the region of Toledo/Paraná.

The second part characterizes the mechanisms of collective action processes among the most active STR in the Semi-Arid Northeast, in terms of family agriculture development. The article concludes with an analysis of the profile and role of rural union leadership.

Key words: producer's organization, collective action, rural unions.

\section{INTRODUÇÃO}

Os Sindicatos de Trabalhadores Rurais (STRs) constituem a principal forma de organização profissional e gremial dos agricultores familiares no Brasil. O presente artigo trata da construção dos processos e dos temas dessa ação coletiva, em dois contextos da agricultura familiar: o oeste do Paraná e o Nordeste semi-árido. As duas situações foram aqui reunidas apenas por oferecer um caráter comparativo entre dois estudos realizados em marcos diferentes, mas a partir de uma preocupação comum: a relação entre a ação coletiva fomentada pelas lideranças dos STRs e a realidade da evolução da agricultura familiar regional, que constitui a base social desses sindicatos. A ação coletiva foi definida por Olson (1966: 13) como a "ação de um grupo de indivíduos que têm interesses comuns, geralmente expressos na defesa de um objetivo comum, ou de um bem coletivo" (tradução nossa). De fato, existe uma relação entre as formas da ação coletiva e as formas das organizações - aqui dos sindicatos - nas quais essas ações são definidas e implementadas.

Crozier e Friedberg (1977: 28) definem a organização como "um processo de criação coletiva através do qual os membros de uma coletividade aprendem juntos. Quer dizer, que inventam e fixam juntos novas maneiras de jogar os jogos sociais da cooperação e do conflito e adquirem as capacidades de conhecimento, de relacionamento e de organização correspondentes" (tradução nossa). Além dos processos de invenção e aprendizagem coletiva e de fixação de regras comuns, o processo de organização é também determinado pelo papel de atores, internos e/ou externos ao grupo. Por isso incorporam-se nessa análise dos sindicatos rurais a dimensão da delegação de poder e de responsabilidade que permite integrar a atuação de tutelas ou influências externas e de lideranças internas ao grupo. Apóia-se aqui, ademais, na hipótese formulada por Ostrom (1992) de coexistência de três modos de coordenação da ação coletiva diversamente realizados e combinados: 1) a delega- 
ção de poder e de responsabilidade; 2) a aprendizagem coletiva; e 3) a regulação, no sentido do estabelecimento de novas regras comuns.

A aprendizagem coletiva, neste sentido, tem a ver com os conhecimentos "coletivizados" que os indivíduos mobilizam para a ação ou organização (Midler, 1994). A noção de aprendizagem corresponde aqui a uma representação da organização que valoriza a experiência e o comportamento dos sujeitos.

Por regulação entendemos a capacidade dos atores em definir e reconhecer regras na perspectiva de um controle efetivo das dinâmicas em jogo e das situações futuras. Os modos de regulação podem ser adquiridos pela transmissão de regras ou de normas, impostos por quadros jurídicos ou por tutelas, ou construídos socialmente via aprendizagem coletiva.

$\mathrm{Na}$ primeira parte deste trabalho, aplica-se esta grade de análise da construção da ação coletiva às formas de evolução da delegação de poder no STR de Toledo (no oeste do Estado do Paraná). Na segunda parte, são analisados os mesmos mecanismos, entre os sindicatos municipais de Pintadas e Juazeiro (na Bahia), Tauá (no Ceará), Petrolina (em Pernambuco) e Lagoa Seca (na Paraíba). Finalmente, comparam-se os perfis das lideranças sindicais e as formas de delegação de poder e de responsabilidades nos dois casos estudados.

\section{EVOLUÇÃO DO SINDICALISMO RURAL E DELEGAÇÃO DE PODER NO OESTE DO PARANÁ}

Este estudo de caso trata das formas de delegação de poder no STR do município de Toledo-PR, para a construção das ações coletivas. As ações correspondem ao "conjunto das atividades desenvolvidas pela entidade sindical, desde a organização da rotina na sede, até a realização de atos de maior impacto, como passeatas ou bloqueio de estradas" (Maduro, 1990:16).
A referência temporal para o estudo foi o desenvolvimento da agricultura do período de fundação do sindicato (1970), até o final dos anos 80. As mudanças na estrutura da agricultura familiar expressam-se na alteração do patamar tecnológico, na compulsão à mercantilização da maioria da produção agrícola e nos processos de seleção/ exclusão ocorridos no meio rural. Nesta etapa, estava sendo implementado, no Paraná, o modelo denominado "modernização conservadora da agricultura1", com a culminância das suas conseqüências nefastas no período dos anos 80 em diante. Procura-se estudar, em paralelo, o perfil da ação da direção sindical e as transformações estruturais em andamento na agricultura que afetam as bases destes sindicatos ${ }^{2}$.

A história da organização sindical dos trabalhadores rurais no Brasil se inicia em 1933, com a criação do primeiro sindicato em Campos/RJ (Pascoalotto-Hachbart, 1989). Porém a mobilização no campo apenas se expandiu após a Segunda Guerra Mundial, intensificando-se a partir da década de 1950. "Neste período, as principais formas de organização eram as ligas camponesas, associações de classe e sindicatos de trabalhadores rurais, difundidos principalmente a partir de variadas organizações políticas e/ou ligadas à igreja católica” (Colognese, 1991: 57). No Paraná, a criação dos primeiros STRs espelha-se nos modelos dos sindicatos do Rio Grande do Sul. Começa de 1964 em diante, com os STRs de Curitiba, Londrina e Ponta Grossa (FETAEP, 1987). Em Toledo, o STR é fundado em 1970, a partir da participação da Frente Agrária Gaúcha (FAG), da ACARPA (hoje EMATER) e do apoio da prefeitura municipal.

Os primeiros movimentos para a fundação do STR de Toledo originaram-se de antigos membros do sindicato patronal, que era então o único que agregava os produtores rurais. Nesta época (final dos anos 60), chega à cidade o padre Aluísio Weber, que "era um grande sindicalista e com grandes experiências já desde a Europa e veio implantar na nossa região o movimento sindical. Ele estava aqui

Este modelo de agricultura tem como objetivo uma mudança na base técnica de produção, que transforma a produção artesanal do camponês, à base da enxada, numa agricultura moderna, intensiva e mecanizada. Este processo foi estimulado pelo programa denominado «Revolução verde» que se propunha a estimular a produção e a produtividade agrícola no mundo, visando ao desenvolvimento de experiências no campo da genética vegetal para a criação e multiplicação de sementes adequadas às condições dos diferentes solos e climas e resistentes às doenças e pragas, bem como da descoberta e aplicação de técnicas ou tratos culturais mais modernos e eficientes. Sobre o assunto, ver Brum (1985), Kageyama (1985), entre outros.

${ }^{2}$ Salienta-se que os depoimentos utilizados são de associados e membros da direção sindical. Os depoimentos foram colhidos através de um roteiro de entrevista semi-estrturado. Para os depoimentos da representação sindical, utilizamos o símbolo R1, e para os representados R2 (os depoimentos estão inseridos dentro do texto de forma original para um maior entendimento e fidelidade da pesquisa). 


\section{4 Eric Sabourin e Miguel Ângelo Lazzaretti}

em Toledo e nós copiamos alguma coisa dele, ouvimos seus pensamentos e suas diretrizes" (R1). Na verdade, o padre Weber tinha chegado até Toledo através de um pedido do então bispo da cidade, Dom Armando Sírio, "que sugeriu lá no Rio grande do Sul que eles mandassem alguém pra a fundação deste sindicato" (R1).

A Igreja mantinha relações com o meio rural no Rio Grande do Sul onde tinha gerado diversos sindicatos de trabalhadores rurais através da $\mathrm{FAG}^{3}$. O interesse da FAG era não deixar espaços para organizações "subversivas” ou de "esquerda" como mediadoras desta organização social dos trabalhadores rurais. Coradini (1988: 416) afirma que, "na medida em que os anos de "autoritarismo" não davam condições de surgimento de heterodoxias e as concorrências eram limitadas, isso possibilitou à igreja católica ter um relativo monopólio sobre este sindicalismo".

Em Toledo não foi diferente. Não houve sequer indícios de outros grupos interessados em organizar o STR. É importante salientar que a igreja iria garantir uma certa continuidade deste sindicalismo após o golpe militar de 1964, pois "as entidades sindicais, tidas como ligadas à igreja, foram num certo ponto poupadas" (Palmeira, 1985: 45). Segundo Bressan (1978), a FAG tinha como principal finalidade desenvolver o espírito de solidariedade social entre os homens do campo, tendo como objetivo a realização da doutrina social cristã. Era, segundo Bressan (1978: 176), sempre vinculada a "encarnar a imagem do evangelho no mundo rural segundo o plano de Cristo". Para isso, a entidade possuía um departamento sindical com a finalidade de fundação de associações de classe, sindicatos de pequenos proprietários e assalariados rurais. " $A$ proposta da FAG tinha condições de atrair os pequenos proprietários rurais, pois estruturava-se a partir da defesa da produção familiar, contra o que se considerava um ataque à propriedade privada promovida pelo MASTER" (Maduro, 1990: 73). Assim, em Toledo, esse sindicalismo dócil, criado pela FAG, ficou divorciado de idéias progressistas e vinculado, essencialmente, com a ordem social vigente. Ainda segundo Bressan (1978: 180), "não houve maiores dificuldades para a FAG fazer com que os agricultores acreditassem que as conseqüências de possíveis mudanças pudessem ser piores que o atual estado vigente, pois toda a idéia de mudança estava vinculada e associada com o comunismo" ${ }^{4}$. A definição de sindicato defendida pela FAG e colocada em prática pelos dirigentes sindicais de Toledo era a do "orientador", com as seguintes funções: "representativo, defensor e reivindicador" (R1).

A delegação de poder a este tipo de lideranças sindicais influenciou as ações do STR, que passou a ser, essencialmente, uma entidade de ajuda social e de prestação de serviço aos trabalhadores. Desta forma, o sindicalismo posto em prática toma um caráter assistencialista e passa a ser implementado e aceito como uma única forma de fazer movimento sindical.

\subsection{A INSTITUCIONALIZAÇÃO SINDICAL COMO ENTIDADE ADMINISTRATIVA-ASSISTENCIAL (1970-80)}

O STR de Toledo vai operar com uma estrutura administrativa centrada nas questões assistenciais. Neste período (1970-1973), os sindicatos rurais passam a receber recursos financeiros do Funrural. Sendo assim, a prestação de serviços por parte do sindicato exigiu que os dirigentes permanecessem, mais efetivamente e em tempo integral, nas sedes sindicais. Esta permanência repercutiu na produção dos objetos de representação; fez com que a produção de temas e ações incidisse num privilegiamento de alguns diretores. Isto significou, concretamente, o aumento da remuneração dos dirigentes (pago sob a forma de gratificações), principalmente, do presidente. Este tipo de consolidação da estrutura sindical fez com que os dirigentes se sobrecarregassem de atividades burocráticas. A figura do presidente passa a ser importante, pois a concentração de atividades e poder nas suas mãos faz com que ele possa permanecer por vários mandatos no cargo 5 .

Após efetivada a consolidação da estrutura física do sindicato - que foi o principal tema e ação dos primeiros anos -, o eixo temático passa a ser centrado em dois nortes fundamentais: a assistência médico-odontológica

\footnotetext{
${ }^{3} \mathrm{O}$ padre Weber era um agente da FAG, entidade criada pelos setores conservadores da Igreja Católica, contra as lideranças religiosas que apoiavam as ligas camponesas ou, no âmbito do Rio Grande do Sul, o MASTER (Movimento dos Agricultores Sem Terra), surgido no início dos anos 1960 com apoio do PC e do PTB. Ver Coradini (1988).

${ }^{4}$ Quando se indagou, durante a pesquisa de campo, a alguns diretores fundadores deste STR, sobre esta questão, eles respondiam: "graças ao bom Deus aqui não tivemos comunistas..."

${ }^{5}$ O STR de Toledo viria a ter, durante praticamente toda sua história, apenas dois presidentes: um que assumiu após a fundação e que ficará no cargo até o ano de 1973, e um segundo, que fica de 1974 até 1997, ano em que faleceu.
} 
e a promoção de cursos diversos. Esta questão passa a ter um lugar definido no discurso e atuação dos dirigentes sindicais. Segundo Coradini (1988: 327), "a saúde e previdência social rural, enquanto preocupação dos sindicatos de trabalhadores rurais, suas federações e confederações, de certo modo, é concomitantemente a sua própria formação e expansão". Neste sentido, a assistência à saúde torna-se o principal objeto de representação sindical. Os dirigentes sindicais tomam, como "único" direito dos trabalhadores rurais, a saúde, "pois você sabe que a situação do nosso trabalhador as vezes não é muito benéfica e a necessidade de ser atendido em problemas de saúde isso que é mais importante" (R1).

Outro benefício prestado pelo STR, e que significou uma adesão importante dos representados, foram as concessões de aposentadorias: "Com a expansão da aposentadoria aos trabalhadores rurais a partir de 1972, o seu encaminhamento junto ao Funrural, e posterior entrega dos carnês de aposentadoria, constituíram momentos decisivos na conquista da adesão dos representados aos sindicatos. Tanto que entre os beneficiados e seus familiares era comum uma certa noção de dívida para com o dirigente sindical, identificado como o responsável pela concessão do benefício (Colognese, 1991: 114-115)”.

Foi neste período que a chamada "modernização tecnológica da agricultura” se expandiu do Rio Grande do Sul para outros estados e atingiu o oeste paranaense de forma intensa. O STR de Toledo, junto com a Prefeitura Municipal (Secretaria da Agricultura), a Emater e a cooperativa, "participam" da promoção dessa modernização ${ }^{6}$. No entender dos dirigentes sindicais, o agricultor, o colono, tinha que mudar de padrão tecnológico: “... A gente trabalhou muito em conjunto com a Emater e ali nós fomos ao campo e fizemos reuniões em conjunto com a Prefeitura (Secretaria da Agricultura), a própria cooperativa e nós fomos ao encontro do nosso produtor, que ele deve mudar, que ele não pode mais trabalhá como antigamente os nossos pais trabalhava senão ele ia ficá prá trás...(R1).

Por outro lado, a questão da reforma agrária era vista como algo "subversivo". Isto se explica pelo perfil ideológico da representação sindical deste período, ou seja, a inculcação arraigada da propriedade privada da terra. Segundo os sócios, não era possível nesta época "aprender sobre reforma agrária” (R2). O período representou a consolida- ção institucional da estrutura de prestação de serviços do STR de Toledo. No entanto, algumas variações começam a aparecer no final dos anos 70, demarcando um processo de ruptura nesse sindicalismo.

\subsection{RUPTURAS E CONTINUIDADES NA DELEGAÇÃO DE RESPONSABILIDADES SINDICAIS (1980-1989)}

A partir dos anos 80, os objetos de representação sindical passam por um processo de ruptura/continuidade. $\mathrm{O}$ conteúdo dos temas e das ações não muda, pelo contrário, o assistencialismo continua como norteador dos ideais da representação sindical, mas a forma evolui. Em 1980, o STR participa de debates sobre a reforma agrária em Curitiba e aproveita este movimento nacional para elaborar um manifesto sobre o confisco da soja, além de promover um protesto na rodovia que beira o município. Esta ruptura nas práticas foi circunstancial, na medida em que os grupos ligados aos dirigentes sindicais eram produtores de soja. A consciência da representação estava ligada apenas a resultados imediatos, como a melhoria do preço da soja. Após os resultados positivos das pressões junto ao governo federal de 1980, o sindicato vai reduzir suas reivindicações e movimentos e voltar às práticas anteriores.

Tratando-se de oposição sindical, durante os dois períodos em questão, apenas uma vez viria a ocorrer um enfrentamento de chapas diferentes, contudo, com o fracasso da chapa de oposição: "A oposição que tivemos aqui sempre perdeu" (R1).

Esta perpétua direção sindical vai demonstrar o caráter empresarial do seu sindicalismo. Um grupo de pessoas, sempre as mesmas, administra o sindicato, menos em função dos interesses coletivos e mais em função de interesses próprios. Por outro lado, estes mesmos dirigentes tentam demonstrar para a sociedade e para os trabalhadores rurais, uma face um tanto empreendedora de lutas sindicais. O Jornal do Oeste, de 23/08/85, ilustra muito bem esta prática: "O STR de Toledo, por sua diretoria, vem de público declarar que sempre esteve e estará solidário com a reforma agrária. Onde quer que o trabalhador rural esteja, nós estaremos a sua frente para representá-lo, defendê-lo e reivindicar a seu favor". O que interessava não era a reforma agrária, mas a imagem que a direção queria passar para as outras organizações e os associados, ou seja, credenciar-se como sindicato reivindicador.

${ }^{6} \mathrm{O}$ processo de modernização da agricultura paranaense, puxado pela cultura da soja, ocorreu de forma veloz. Em apenas dez anos, expandiu-se e consolidou-se. O reflexo deste processo na região oeste (que fora recentemente colonizada) resultou na expulsão de milhares de pequenos produtores rurais e no aumento acentuado do número de bóias-frias (ver Brum, 1985). 
Assim, o que se podia constituir como ruptura dos objetos de representação sindical aponta para uma continuidade, na qual os temas e ações aparecem com a mesma conotação distante da realidade da evolução da agricultura regional e das prioridades dos trabalhadores rurais.

\subsection{A APRENDIZAGEM COLETIVA EM TOLEDO}

Este resgate deveria compreender a dinâmica das transformações que ocorreram na agricultura brasileira. Ou seja, a agricultura, transformando-se, de um lado, com suas conseqüências e, de outro, a representação sindical, produzindo temas e ações para este sindicalismo.

Nos dois períodos analisados, a ação coletiva promovida pelo STR de Toledo se restringiu à atuação em torno de objetivos ligados apenas à representação sindical. Não houve uma interlocução que promovesse uma discussão aprofundada sobre os problemas relacionados diretamente à agricultura familiar. $\mathrm{O}$ que norteou, basicamente, a ação deste sindicato foi a promoção de assistencialismo, que, de certa forma, reproduzia as políticas governamentais para a agricultura. Os cursos de corte e costura e de suinocultura foram os mais frisados e destacados, nos relatórios anuais e vinculados aos programas ditos de educação sindical.

O STR de Toledo vai operar, como afirmado anteriormente, desde sua gênese, com uma estrutura administrativa centrada em torno dos interesses dos dirigentes, mantendo sempre à margem os representados. $\mathrm{Na}$ verdade, ocorreu apenas um monólogo na relação direção/associados, pois o que interessava era apenas a construção de uma imagem representativa perante a sociedade e, por outro lado, o que importava era o bem-estar da direção, vinculado aos interesses do Estado. Parafraseando a expressão de Grzybowski (1990), foi uma direção ao lado do Estado e longe dos trabalhadores rurais.

\subsection{O ESTABELECIMENTO DE NOVAS REGRAS}

O estabelecimento de novas regras comuns constitui um processo finalizatório em torno da ação coletiva. No STR de Toledo, desde o momento de sua fundação estabeleceram-se regras práticas e formais vinculadas a determinações advindas do modelo de organização sindical prescrito pelo Estado. Isto significou um combate à ideologia camponesa na forma que os movimentos sociais a concebem, ou seja, de respeito às determinações inerentes à unidade familiar tradicional.

As regras sempre foram formuladas com antecedência, e o principal para os associados, estava na adaptação destas, que muitas vezes eram aplicadas sem que houvesse um questionamento prévio de sua aceitação. As regras, formalizadas ou não, escritas ou não, constituem uma maneira de reduzir ou evitar conflitos. São feitas para serem respeitadas, mas também são inevitavelmente criticadas, transgredidas, quando não são mais adaptadas à realidade. Há necessidade, portanto, de um novo consenso em torno de novas regras comuns.

O principal mecanismo de regulação, que permite à organização continuar a funcionar e a existir em um ambiente em transformação permanente, reside precisamente na capacidade do grupo em elaborar e adaptar novas regras coletivas. No entanto, o que se viu no STR de Toledo foi a imposição de normas pelo grupo dirigente. Nesse sentido, sem a reelaboração coletiva de novas regras comuns, provavelmente, este sindicato tenderá a perder sua capacidade de aglutinação dos trabalhadores rurais e, conseqüentemente, poderá entrar em estado de anomia até que novos dirigentes, com outra concepção de sindicato, tomem o lugar dos atuais, e que novas regras possam ser construídas coletivamente.

\section{CONSTRUÇÃO DA AÇÃO COLETIVA ENTRE OS SindiCATOS RURAIS DO NORDESTE SEMI-ÁRIDO}

\subsection{ORIGEM DOS SINDICATOS NORDESTINOS E DELEGAÇÃO DE RESPONSABILIDADES}

Na zona semi-árida do Nordeste, a maioria dos STRs, criados durante o regime militar, conquistou mais autonomia a partir dos anos 1980. Podem ser distinguidas duas principais origens dos STRs no Nordeste: as lutas trabalhistas e fundiárias dos assalariados, mas, sobretudo, dos parceiros (moradores, meeiros e arrendatários); e os programas de assistência social e médica promovidos pelo Estado. De fato, este transferiu para os STRs a gestão da assistência médica no meio rural, de maneira a desviá-los de sua função de reivindicação, sem, no entanto, proibi$\operatorname{los}^{7}$. Outra influência ou tutela determinante, além do

\footnotetext{
${ }^{7}$ A nova Constituição Federal (1988) fez a mesma coisa com a administração local da aposentadoria rural. Esta função continua a mobilizar os esforços das lideranças sindicais, em detrimento da ação sindical.
} 
Estado ou dos delegados das federações, durante o período militar, foi a Igreja Católica. Em Tauá e Pintadas, ela apoiou os agricultores e o STR contra as oligarquias. No caso de Lagoa Seca, no Brejo da Paraíba, além do interesse pela manutenção do projeto de assistência médica, criado pela paróquia, tratava-se de fundar um sindicato com uma diretoria moderada, favorável à Igreja, antes que este fosse formado por elementos mais radicais. Pesou a história da criação do STR de Campina Grande, entre 1958 e 1962, marcada pela concorrência acirrada entre os candidatos da Igreja e aqueles das Ligas Camponesas.

Assim, mesmo para a criação e organização dos STR mais atuantes e radicais da região, houve, no início, delegação de responsabilidade a tutelas e atores externos. Durante o período militar, os delegados sindicais nomeados pelas federações estaduais tinham o poder de criar sindicatos municipais, indicando e nomeando os membros da diretoria fundadora, como foi o caso em Lagoa Seca. Por acaso, neste município, a fundação do STR, em 1971, foi complicada por rivalidades entre a Prefeitura Municipal (MDB), a Igreja Católica e até entre assessores e delegados da própria federação estadual da Paraíba.

Entre os sócios de um STR, a delegação de poder e de responsabilidade para membros do grupo está associada, ao mesmo tempo, à noção que eles têm da representação dos seus interesses coletivos e ao reconhecimento de uma autoridade competente. Esta autoridade "representativa” permanece, ainda hoje, muitas vezes externa ao grupo local de produtores, podendo atuar como aliança ou como tutela. Certas alianças parecem a priori paradoxais. Nos perímetros irrigados de Maniçoba e Curaça (Juazeiro-BA), os "colonos" membros do STR, para reivindicar os títulos de propriedade dos seus lotes, chamaram o Movimento dos Sem-Terra, melhor preparado que suas organizações para este tipo de ação.

\subsection{A APRENDIZAGEM COLETIVA NESTAS INSTITUIÇÕES}

Os sindicatos que se destacam na região passaram, em um momento ou outro, por uma fase de luta trabalhista e/ou fundiária, propícia para forjar uma experiência coletiva na prática e, portanto, para esclarecer ou priorizar os tais “objetivos comuns" (Olson, 1966). Esta dimensão constitui a primeira forma de aprendizagem coletiva. As organizações constroem-se na prática da experiência coletiva e seu perfil acaba sendo modelado por esta prática. Foi verificada a existência de três práticas fundadoras principais: as lutas fundiárias e trabalhistas, assistência social (médica ou aposentadoria) e o apoio à produção familiar.
Os conflitos trabalhistas no Sertão dos Inhamuns, no Ceará (Tauá) e no Brejo da Paraíba (Lagoa Seca) motivaram a criação do sindicato nos anos 70. Em PintadasBA, foi a exacerbação das lutas fundiárias contra "grileiros" nos anos 80 que radicalizou e renovou a atuação do STR. Ao contrário, os sindicatos de Petrolina e Juazeiro, os dois principais municípios do Sertão do São Francisco, tiveram suas atividades polarizadas por ações trabalhistas e pela existência de uma forte concentração de trabalhadores assalariados das empresas de irrigação. São, de fato, pouco atuantes junto aos pequenos proprietários ou quanto a temas ligados à produção familiar. Paradoxalmente, são pouco radicalizados, quando não considerados publicamente como "pelegos". Isto pode ser explicado, em parte, pelas influências ou até alianças entre as diretorias destes sindicatos e as próprias empresas irrigadas, as lideranças políticas locais ou a corporação trabalhista (advogados, juízes etc).

Esta moderação explica por que pequenos produtores dos perímetros irrigados (não assalariados, mas os colonos beneficiários de lotes) tenham que recorrer aos movimentos dos sem terra (MST e MLT) para casos de reivindicação contratual ou fundiária junto ao Estado.

No caso de sistemas em mutação, se os conhecimentos comuns não estão adquiridos, devem ser construídos. A aprendizagem coletiva passa, geralmente, por um período de alternância entre sucessos e fracassos, que permitem criar referências locais. Este mecanismo pode ser assimilado, em termos coletivos, à racionalidade "processual" ou subjetiva definida por Simon (March e Simon, 1971). Porém, num contexto de circulação da informação bastante difícil, esta construção passa por uma sucessão de experiências e ajustes. Por exemplo, foram as lutas pela terra dos anos 70 (defesa de posseiros e meeiros) que levaram os sindicatos de Tauá-CE e Lagoa Seca-PB a se preocupar com o uso da terra e o apoio à produção, de maneira a se posicionarem, anos mais tarde, nos anos 90, em prol de uma política pública específica para as categorias da agricultura familiar.

\subsection{O ESTABELECIMENTO DE REGRAS}

Também aqui o estabelecimento de novas regras comuns constitui já uma finalização de processos de decisão coletiva, construídos e interpretados no decorrer da ação. As regras são traduzidas pela formulação de medidas consensuais (turnos e tarefas na diretoria, regulamento interno) ou impostas (estatutos, legislação federal), escritas ou não (ordem de tomada de palavra nas reuniões)

Raízes, Campina Grande, vol. 21, nº 01, p. 72-80, jan.jjun. 2002 
e pela implementação de mecanismos que permitem verificar sua aplicação.

De uma maneira geral, as regras, sobre as quais se apóiam os atores, respondem a quatro características principais (Favereau, 1994). Primeiro, são respostas a questões práticas: com que recursos vai funcionar o sindicato? Como cobrar a taxa dos sócios? Como proceder para renovar a diretoria? Segundo, as regras constituem modelos para serem validados: a conformidade nunca é automática. Favereau (1994) lembra que a regra "não é uma solução já pronta (...) mas um processo de investigação e adaptação" (tradução nossa). Além disso, existe certa flexibilidade na interpretação dos estatutos ou do regulamento entre os sindicatos, em particular para as eleições da diretoria. Existem, também, tentativas de transgressão das regras pelos indivíduos.

A terceira característica a ser observada é que as regras são ferramentas que aumentam a capacidade de ação individual. Tornou-se aqui o exemplo do STR do município de Tauá: consolidado nas lutas agrárias da região dos Inhamuns e na obtenção de melhores condições para o meeiros e parceiros, permitiu que estes se tornassem pequenos proprietários. De "sem-terra”, a base majoritária passou a pequenos proprietários, defendendo novos interesses em prol da produção familiar. O STR de Tauá fez votar uma lei agrária municipal em 1990, organizou comissões tecnológicas, grupos de interesse sobre manejo de água, algodão Moco e caprinos e conseguiu assumir a Secretaria Municipal da Agricultura.

A quarta e última característica é que as regras não são fixas, mas dinâmicas; são sujeitas a críticas e ajustes. Verifica-se também nestes casos que o principal mecanismo de regulação, que permite à organização continuar a funcionar e a existir num ambiente em transformação permanente, reside precisamente na capacidade do grupo para elaborar e adaptar novas regras coletivas. Por exemplo, em Tauá, os membros da diretoria que se beneficiaram de numerosos treinamentos e que permitiram melhorar sua situação produtiva, passaram a ser questionados e criticados pelas bases de pequenos produtores. Isto foi, em particular, a situação constatada em regiões como a Serra dos Inhamuns, dominada por fazendeiros e onde continua a prática da meia. Assim, para legitimar a sua orientação e ampliar o número de beneficiários da sua ação coletiva, o STR de Tauá, a partir de 1993, coordenou várias intervenções de instituições técnicas públicas e não-governamentais para elaborar um plano de desenvolvimento agro-ecológico municipal. Mas o poder de administração destes fundos e projetos continuava na mão da diretoria do STR. Houve críticas e reclamações também, por parte das instituições financeiras e do poder político local. Então, a partir de 1995, o STR transferiu a administração do plano para os conselhos e as associações de produtores.

Os projetos coletivos constroem-se, portanto, no quadro de negociações permanentes. Esta negociação não pode ser desprezada ou sub-avaliada, porque contribui para o estabelecimento de acordos consensuais ou majoritários e para uma apropriação comum dos objetos e das referências associados à ação coletiva.

Esses três modos de construção da ação coletiva são aqui apresentados separadamente, como se fossem fases sucessivas de um processo. De fato, existe uma dinâmica, mas esta não é linear ou seqüencial, pois, sempre existe delegação de poder, mesmo no seio de uma organização burocratizada e regulamentada. A aprendizagem coletiva é permanente, indissociável de toda a ação coletiva. Da mesma maneira, as reações contra as "antigas" regras ou as críticas das normas existentes levam a novos fenômenos de regulação. Estes aparecem também em razão das transformações do contexto, do acesso à informação ou do enfraquecimento próprio a qualquer sistema de regras. Se existe um processo, ele é cíclico e iterativo.

\section{CONCLUSÃO}

A delegação de poder no seio do sindicato é associada aos líderes, sejam eles dirigentes eleitos ou autoridades das organizações camponesas. Segundo Olson (1966), que estudou especificamente os movimentos sindicais, a ação coletiva seria, muitas vezes, de fato, uma "minoria não representativa do grupo", na medida em que a maioria dos membros espera que os outros atuem, de maneira a ter acesso ao bem coletivo sem esforço, em caso de sucesso, ou sem correr risco, em caso de fracasso. Este postulado esclarece várias situações nas quais os animadores de operações de desenvolvimento comunitário avaliam fracassos, na ausência de uma mobilização majoritária do grupo na base. Contribui, entre outros fatores, a relativizar o paradigma da participação e a explicar, em parte, o papel da liderança.

Os líderes são, geralmente, os produtores que têm os meios e a vontade de "correr riscos", ou boas razões para tal. A ação coletiva depende, muitas vezes, da existência de um núcleo de indivíduos particularmente motivados, ativos e interessados. São os que possuem recursos sufici- 
entes, mas também capacidade de antecipação, para redistribuir seu tempo e suas idéias; são, por exemplo, agricultores que podem contar com a mão-de-obra familiar, ou que têm como contratar alguém para substituí-los, quando precisam viajar, ou participar de reuniões.

Além da facilidade de falar e do carisma pessoal, que são os atributos essenciais das lideranças camponesas, estas acumulam, geralmente, quatro outras caraterísticas: uma experiência de migração urbana; uma atuação militante nas estruturas da Igreja Católica; uma situação econômica mais ou menos estabilizada (posse de terras, rebanho, aposentadoria ou pequeno negócio); e uma posição de intermediário político ou de "cabo eleitoral”.

Para a organização da produção ou da ação coletiva, além de convencer, o líder deve saber reunir recursos, meios e homens. Para captar recursos, opera muitas vezes a conjunção entre carisma do discurso comunitário e interesse individual. Da combinação entre interesse individual da liderança e interesse coletivo podem nascer confusões, gerando desvios e corrupção. Desvios para interesses privados em nome do bem coletivo são relativamente tolerados nos pequenos grupos, por duas razões: a função de dirigente não é remunerada e cada um espera poder aproveitar das suas relações de proximidade com o líder, reproduzindo o esquema clientelista nordestino (Sabourin et alii, 1996).

No caso do STR de Toledo-PR, o perfil das lideranças é caracterizado pela prática paternalista de favores e pela permanência de regras preestabelecidas por tutelas. Segundo a FAG, o líder deve ser firme e religioso, ser honesto, ter conhecimento das leis e ter cursos pela própria federação (Bressan, 1978). Isto marca, de maneira bastante rígida, o universo dos selecionáveis aos cargos dirigentes. A FAG também construíra um perfil definido dos representados: "pois afinal de contas é o pequeno produtor que precisamos conscientizar, é ele que está produzindo" (R1). Ou seja, por mais que se enquadrassem nos trabalhadores rurais, bóias-frias, sem-terras e assalariados, a categoria privilegiada era a do pequeno proprietário.

Ainda no caso de Toledo-PR, a atuação do STR mostrou um falso processo de participação, não integrou a comunidade rural ao processo de desenvolvimento, nem defendeu os interesses da maioria dos trabalhadores rurais da região. As ações e os temas, propostos ou impostos pelos dirigentes sindicais de Toledo, procuravam agradar às tutelas locais, satisfazer aos interesses de uma minoria de sócios (no caso os "colonos") e manter-se no poder.
O interesse de um pequeno grupo sempre prevaleceu, em detrimento de uma maioria de trabalhadores rurais, que sempre se manteve alienada da sua verdadeira problemática. Seus "direitos” se circunscreveram ao perfil adotado pela representação sindical. Esta, por sua vez, não promoveu nenhuma informação ou educação das bases, no sentido de compreender o que estava ocorrendo na região, no período da modernização da agricultura familiar. A aprendizagem coletiva das bases foi limitada ou existiu à revelia do sindicato.

Mudanças técnicas e mudanças sociais são estreitamente ligadas ao processo de organização dos agricultores familiares. Através dos STRs, mas também das cooperativas e associações, novas formas de organização, promovidas em parte pela intervenção externa, foram acompanhando as transformações da agricultura familiar. Em função da relação entre o controle realmente exercitado pelas bases camponesas e as influências alheias, essas novas instituições rurais tiveram um papel acelerador, regulador ou, ao contrário, bloqueador dos mecanismos de organização coletiva e autonomia das comunidades rurais.

\section{REFERÊNCIAS BIBLIOGRÁFICAS}

BRESSAN, Suimar J. Sindicalismo rural e sociedade: relações e história. Porto Alegre, UFRGS, Diss. de Mestrado em Sociologia, 1978.

BRUM, Argemiro. Modernização da agricultura: o binômio trigo e soja. Ijuí, Ed. Unijuí, 1985.

COLOGNESE, Silvio. A produção da representação sindical. Porto Alegre, UFRGS, Diss. de Mestrado em Sociologia, 1991.

CORADINI, Odaci. Representações sociais e conflitos nas políticas de saúde e previdência social rural. Rio de Janeiro, Museu Nacional/UFRJ, Tese de Doutoramento PPGAS/ Museu Nacional/UFRJ, 1988.

CROZIER, M., \& FRIEDBERG, E. L'acteur et le système. Paris-França, Le Seuil, 1977, 500p.

FAVEREAU, O. Règle, organisation et apprentissage collectif: un paradigme non standard pour trois théories hétérodoxes. In: Analyse Economique des Conventions. Orléan A. (Dir.), Paris: PUF, 1994, p. 115-137.

Raízes, Campina Grande, vol. 21, nº 01, p. 72-80, jan./jun. 2002 
FETAEP. Histórico do movimento sindical. Curitiba, 1987 (mímeo).

JORNAL DO OESTE. STR de Toledo na defesa da reforma agrária. Toledo, 23/08/85.

KAGEYAMA, Angela et al. O novo padrão agrícola brasileiro: do complexo rural aos complexos agroindustriais. São Paulo, USP, 1985 (mímeo).

GRZYBOWSKI, Cândido. Caminhos e descaminhos dos movimentos sociais no campo. Petrópolis: Vozes, 1990, 90p.

MADURO, Acácia. A prática sindical da Fetag. Porto Alegre, UFRGS, Diss. de Mestrado em Sociologia, 1990.

MARCH, J. G., \& SIMON, H. A Les organisations. ParisFrança: Dunod, 1971, 254p.

MIDLER, C. Evolution des règles de gestion et processus d'apprentissage. In: Analyse Economique des conventions, Orléan A. (Dir), Paris-França: PUF, 1994, p.335-369.

OLSON, Mancur. The logic of collective action: public goods an the theory of groups. Massachussets, USA: Harvard University Press, 1966, 111p.

OSTROM, Elinor. Crafting Institutions for self-governing irrigation systems. San Francisco - USA: ICS Press, Institute for Contemporary Studies, 1992, 111p.

PALMEIRA, Moacir. A diversidade da luta no campo: luta camponesa e diferenciação do campesinato. In: PAIVA, Vanilda. Igreja e questão agrária. São Paulo, Loyola, 1985.

PASCOALOTTO, Derci \& HACKBART, Rolf. $O$ sindicalismo rural está em crise. Curitiba, 1989 (mímeo).

SABOURIN, E. TONNEAU, J. P, CARON, P. Farmer's organizations and access to innovations: pathways of socio-economic change in Massaroca (Bahia State - Brazil). In: Changing Agricultural Opportunities: the role of farming systems approaches - proceedings of 14th International Symposium on Sustainable Farming Systems, AFSR/E, Colombo, Sri Lanka, 11-16 nov. 1996, pp. 140-147. 